\title{
Pemanfaatan IPTEK Dalam Kegiatan Belajar Mengajar Untuk Masyarakat Pela Mampang Di Masa Pandemi
}

\author{
Andi Saryoko, Retno Sari, Verry Rianto, Susy Rosyida \\ Sekolah Tinggi Manajemen Informatika dan Komputer Nusa Mandiri \\ Email: andi.asy@nusamandiri.ac.id, 085777330434
}

\begin{abstract}
Abstrak
Di masa pandemi covid-19 saat ini, Kami selaku Dosen dan PPPM (Pusat Penelitian dan Pengabdian Masyarakat) Sekolah Tinggi Manajemen Informatika dan Komputer Nusa Mandiri ingin melakukan pengabdian masyarakat dengan memberikan pelatihan kepada warga RT 008/010 Pela Mampang dengan tema pemanfaatan IPTEK dalam kegiatan belajar mengajar terutama pada di masa pandemi. Pelatihan ini bertujuan untuk mengajarkan para warga RT 008/010 Pela Mampang bagaimana menggunakan aplikasi pembelajaran daring, agar dapat membantu para warga RT 008/010 Pela Mampang dalam melakukan kegiatan belajar mengajar selama pandemi. Metode dalam kegiatan pengabdian masyarakat yang dilaksanakan adalah berupa webinar/workshop secara online memberikan pengetahuan dan keterampilan dasar belajar menggunakan aplikasi pembelajaran daring yaitu Google Classroom, melakukan penyampaian materi berkenaan dengan pengenalan Google Classroom, menjelaskan bagaimana langkah-langkah memulai Google Classroom dan apa saja yang dapat dilakukan dengan Google Classroom, memberikan latihan mengakses Google Classroom dan memulai kegiatan belajar. Hasil dari kegiatan pelatihan ini adalah peningkatan keterampilan peserta terhadap pengenalan penggunaan Google Classroom yang memudahkan sebagai tambahan ilmu yang bisa diterapkan pada kegiatan belajar. Kesimpulan dari kegiatan pengabdian masyarakat yang dilakukan adalah 1) Pengabdian masyarakat banyak memberikan manfaat antara lain tercapainya peningkatan keterampilan peserta terhadap pengenalan penggunaan Google Classroom yang memudahkan sebagai tambahan ilmu yang bisa diterapkan pada kegiatan belajar, 2) dengan adanya kegiatan pengabdian masyarakat ini para peserta dapat mengoperasikan Google Classroom untuk mendukung proses belajar secara daring selama pandemi, 3) akhirnya para peserta dapat mengajari teman-temannya yang lain, yang belum bisa mengoperasikan Google Classroom untuk kegiatan belajar di sekolah.
\end{abstract}

Kata Kunci: IPTEK, warga pela mampang, pandemic covid-19

\section{Abstract \\ During the current Covid-19 pandemic, we as Lecturers and PPPM (Center for Research} and Community Service) of the Nusa Mandiri School of Information and Computer Management want to carry out community service by providing training to residents of $R T$ 008/010 Pela Mampang with the theme of using science and technology in activities learning and teaching especially during the pandemic. This training aims to teach residents of $R T$ 008/010 Pela Mampang how to use bold learning applications, in order to help residents of RT 008/010 Pela Mampang in carrying out teaching and learning activities during the pandemic. The method in community service activities carried out is in the form of online 
webinars/workshops providing basic knowledge and learning skills using a bold learning application, namely Google Classroom, delivering material regarding the introduction of Google Classroom, explaining how to start with Google Classroom and what can be done with Google Classroom, provide practice accessing Google Classroom and start learning activities. The result of this training activity is an increase in the skills of training participants to use Google Classroom which makes it easier to add knowledge that can be applied to learning activities. The conclusions of the community service activities carried out are 1) Community service provides many benefits, including the achievement of an increase in the skills of participants in the introduction of the use of Google Classroom which makes it easier as additional knowledge that can be applied to learning activities, 2) with this community service activity participants get Google Classroom to support the online learning process during the pandemic, 3) finally the participants can teach other friends, who are not yet able to operate Google Classroom for learning activities at school.

Keywords: Science and technology, pela mampang residents, covid-19 pandemic

\section{PENDAHULUAN}

Setiap inovasi ditujukan untuk memberikan manfaat yang positif bagi kehidupan dan memberikan banyak kemudahan. Inovasi dan perubahan memiliki implikasi yang sangat luas salah satunya di bidang pendidikan yaitu perubahan dalam kegiatan belajar serta menuntut pengintegrasian TIK dalam kegiatan pembelajaran. IPTEK (IImu Pengetahuan dan Teknologi) dapat memberikan kontribusi dalam penguatan perekonomian dan peningkatan kesejahteraan masyarakat. Teknologi dapat meningkatkan kualitas dan jangkauan apabila digunakan secara bijak untuk pendidikan dan latihan, dan mempunyai arti yang sangat penting bagi kesejahteraan.

RT 008/010 Pela Mampang merupakan sebuah pemukiman warga yang berada di Mampang Prapatan Jakarta Selatan yang tepatnya berada pada Jalan Bangka IX A Ujung Rt 008/010 Pela Mampang, Kecamatan Mampang Prapatan, Kota Jakarta Selatan, Daerah Khusus Ibu kota Jakarta 12720. Pemukiman ini memiliki warga yang anak-anaknya sedang melakukan kegiatan belajar mengajar secara daring. Para warga yang merupakan orang tua dan anak-anak SD, SMP dan SMA ini masih memerlukan pelatihan dalam menggunakan aplikasi pembelajaran daring, dikarenakan selama ini mereka melakukan proses belajar mengajar tatap muka dan tidak pernah menggunakan aplikasi pembelajaran daring.

Menurut (Keguruan \& Universitas Tadulako, n.d.) bahwa guru juga masih perlu pelatihan dan pembelajaran, sehingga terlebih anak-anak sekolah. Menurut (Amalia, Retnasari, \& Rachmawati, 2020) pada dasarnya Teknologi informasi adalah sebuah alat yang dapat dimanfaatkan untuk peningkatan pelayanan institusi pendidikan, begitu juga untuk anak-anak didik/murid-murid. Menurut (Hariyanto \& Wahyuni, 2020) Tujuan yang ingin dicapai dari pengabdian yang sudah dilaksanakan adalah meningkatkan pemahaman dan pengetahuan masyarakat.

Oleh karena itu, kami selaku Dosen dan PPPM (Pusat Penelitian dan Pengabdian Masyarakat) Sekolah Tinggi Manajemen Informatika dan Komputer Nusa Mandiri ingin melakukan pengabdian masyarakat dengan memberikan pelatihan kepada warga RT 008/010 Pela Mampang dengan tema pemanfaatan IPTEK dalam kegiatan belajar mengajar untuk masyarakat pela mampang di masa pandemi. Pelatihan ini bertujuan untuk mengajarkan para warga RT 008/010 Pela Mampang bagaimana menggunakan aplikasi pembelajaran daring, 
agar dapat membantu para warga RT 008/010 Pela Mampang dalam melakukan kegiatan belajar mengajar selama pandemi.

\section{BAHAN DAN METODE}

Bentuk dari kegiatan pengabdian masyarakat yang dilaksanakan adalah berupa webinar/workshop memberikan pengetahuan dan keterampilan dasar belajar menggunakan aplikasi pembelajaran daring yaitu Google Classroom untuk menunjang kegiatan belajar secara daring selama pandemi covid-19 kepada warga RT 008/010 Pela Mampang. Jumlah peserta yang hadir adalah 14 orang rata-rata anak-anak SMP dan SMA yang di dominasi oleh peserta perempuan. Dalam kegiatan ini dilakukan penyampaian materi berkenaan dengan pengenalan Google Classroom, menjelaskan bagaimana langkah-langkah memulai Google Classroom dan apa saja yang dapat dilakukan dengan Google Classroom, Memberikan latihan mengakses Google Classroom dan memulai kegiatan belajar. Adapun metode yang dilakukan adalah webinar secara online menggunakan aplikasi Zoom meeting dengan link zoom: https://zoom.us/i/94720393920?pwd=K09yVGhnQ1dLQXNVaytWSGZDcitSZz09 dan Meeting ID: 94720393920 Passcode: 441592. Kegiatan dimulai dengan pembukaan dan sambutan selanjutnya penyampaian materi oleh tutor dan diakhiri dengan diskusi atau tanya jawab dari para peserta.

\section{HASIL}

Hasil dari kegiatan pelatihan ini adalah warga RT. 008/010 Pela Mampang khususnya yang berusia sekolah dapat meningkatkan keterampilan menggunakan Google Classroom, sehingga bisa diterapkan dalam kegiatan yang terkait dengan penggunaan materi tersebut, yang dapat menunjang proses belajar secara daring selama pandemi saat ini. Sementara itu, luaran dari kegiatan ini antara lain Peningkatan keterampilan peserta terhadap pengenalan penggunaan Google Classroom yang memudahkan sebagai tambahan ilmu yang bisa diterapkan pada kegiatan belajar, Para peserta dapat mengoperasikan Google Classroom untuk mendukung proses belajar secara daring selama pandemi, Para peserta dapat mengajari teman-temannya yang lain, yang belum bisa mengoperasikan Google Classroom untuk kegiatan belajar di sekolah. Menurut para peserta kegiatan ini sangat bermanfaat dan sangat memuaskan, terbukti pada dokumen dan hasil kuesioner dari peserta(Dokumen terlampir).

\section{PEMBAHASAN}

Dalam meningkatkan keterampilan peserta terhadap pengenalan penggunaan Google Classroom yang memudahkan sebagai tambahan ilmu yang bisa diterapkan pada kegiatan belajar, maka anak-anak dan orang tua mau tidak mau, suka tidak suka, saat ini sudah semestinya mengenal teknologi terutama dapat mengoperasikan Google Classroom untuk mendukung proses belajar secara daring selama pandemi.

Di masa pandemi covid-19 saat ini, masyarakat terutama anak-anak yang bersekolah maupun orang tua dipaksa untuk bisa menggunakan teknologi untuk melakukan kegiatan belajar mengajar secara daring. Kegiatan belajar daring ini membuat sebagian anak-anak atau orang tua mempelajari teknologi yang digunakan secara otodidak.

\section{KESIMPULAN DAN SARAN}


Kesimpulan dari kegiatan pengabdian masyarakat yang dilakukan secara daring dengan media zoom meeting pada warga Pela Mampang, Jakarta Selatan adalah sebagai berikut:

a. Tercapainya peningkatan keterampilan peserta terhadap pengenalan penggunaan Google Classroom yang memudahkan sebagai tambahan ilmu yang bisa diterapkan pada kegiatan belajar.

b. Para peserta dapat mengoperasikan Google Classroom untuk mendukung proses belajar secara daring selama pandemi.

c. Para peserta dapat mengajari teman-temannya yang lain, yang belum bisa mengoperasikan Google Classroom untuk kegiatan belajar di sekolah.

Diharapkan pada pelaksanaan kegiatan pengabdian masyarakat di waktu yang akan datang, kami selaku para dosen program studi Teknik Informatika Sekolah Tinggi Manajemen Informatika dan Komputer Nusa Mandiri, dapat memberikan sumbangsih ilmu lainnya khususnya yang berkaitan dengan teknologi informasi, sehingga dapat bermanfaat terhadap masyarakat pada umumnya, dan civitas Sekolah Tinggi Manajemen Informatika dan Komputer Nusa Mandiri pada khususnya.

\section{UCAPAN TERIMA KASIH}

Kami segenap panitia pengabdian masyarakat mengucapkan terimakasih kepada pihak-pihak terkait terutama kepada Ketua dan Wakil Ketua Sekolah Tinggi Manajemen Informatika dan Komputer Nusa Mandiri, Pusat Penelitian dan Pengabdian Masyarakat (PPPM) Nusa mandiri, Rekan-rekan Dosen dan civitas akademika yang tidak bisa kami sebutkan satu persatu, Bapak RT. 008/010 Pela Mampang yang sudah mengijinkan kami untuk melakukan pengabdian masyarakat pada warganya, Para peserta warga RT. 008/010 Pela Mampang yang sudah berkenan mengikuti kegiatan dari awal sampai akhir acara, dan yang lainnya yang sudah membantu mewujudkan kelancaran kegiatan pengabdian masyarakat.

\section{DAFTAR PUSTAKA}

Amalia, H., Retnasari, T., \& Rachmawati, S. (2020). Pemanfaatan Teknologi Informasi Untuk Meningkatkan Pelayanan Akademik Rumah Tahfidz Dan Tpq Sakinah Cipayung Jakarta Timur. Jurnal Abdimas BSI: Jurnal Pengabdian Kepada Masyarakat, 3(2), 228-235. https://doi.org/10.31294/jabdimas.v3i2.8550

Hariyanto, E., \& Wahyuni, S. (2020). Sosialisasi Dan Pelatihan Penggunaan Internet Sehat Bagi Anggota Badan Usaha Milik Desa (Bumdes) Mozaik Desa Pematang Serai. Jurnal Abdimas BSI: Jurnal Pengabdian Kepada Masyarakat, 3(2), 253-259. https://doi.org/10.31294/jabdimas.v3i2.8449

Keguruan, F., \& Universitastadulako, I. P. (n.d.). Abdimas Umtas: Jurnal Pengabdian Kepada Masyarakat LPPM-Universitas Muhammadiyah Tasikmalaya, (2), 154-161.

\section{LAMPIRAN}

Berikut gambar yang kami dokumentasikan saat pelaksanaan Pengabdian Masyarakat berupa webinar memberikan pengetahuan dan keterampilan dasar belajar menggunakan aplikasi pembelajaran daring yaitu Google Classroom untuk menunjang kegiatan belajar secara daring selama pandemi covid-19 kepada warga RT 008/010 Pela Mampang 


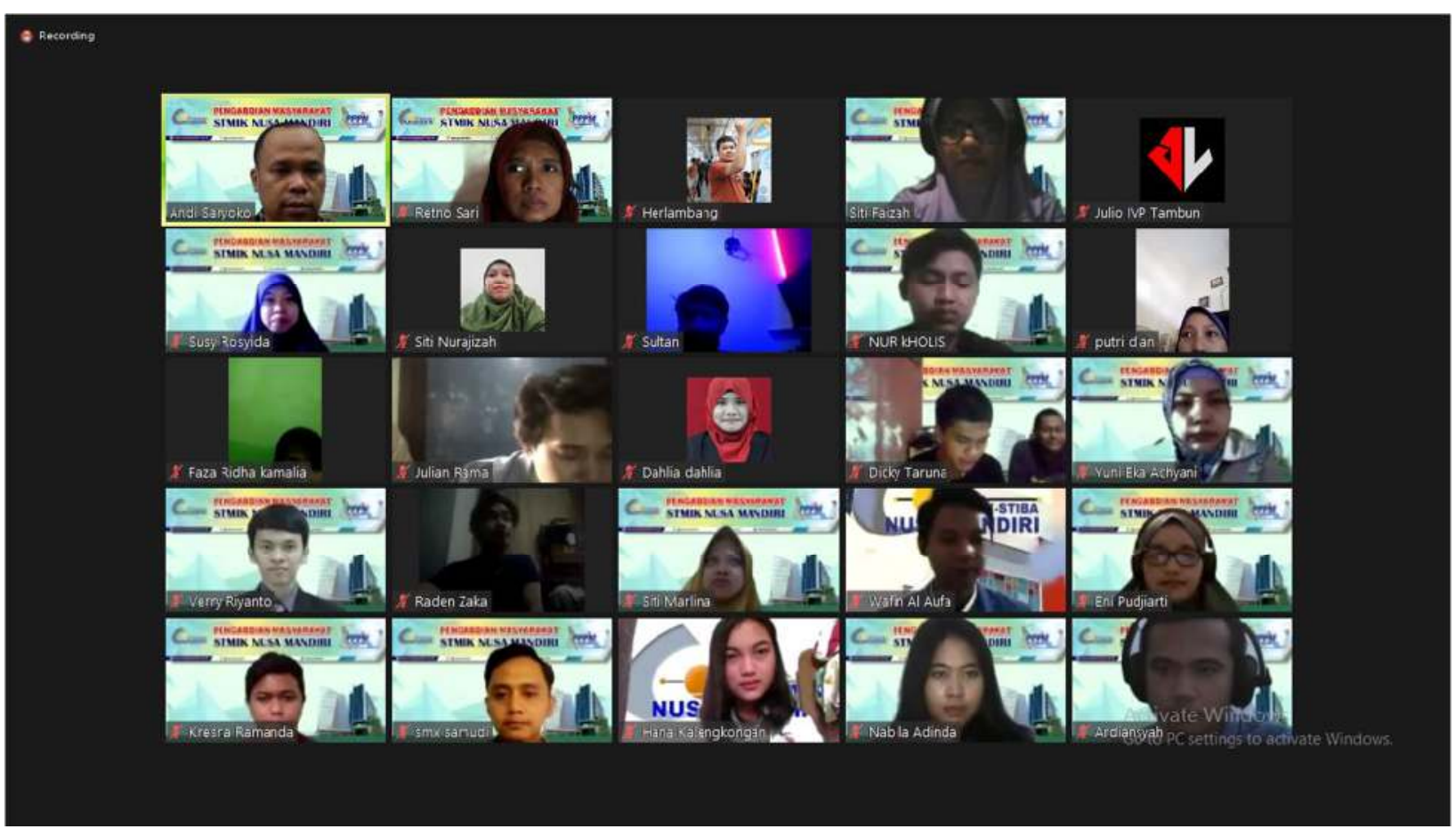

Sumber: Dokumentasi PM

Gambar 1. Dokumentasi pelaksanaan PM

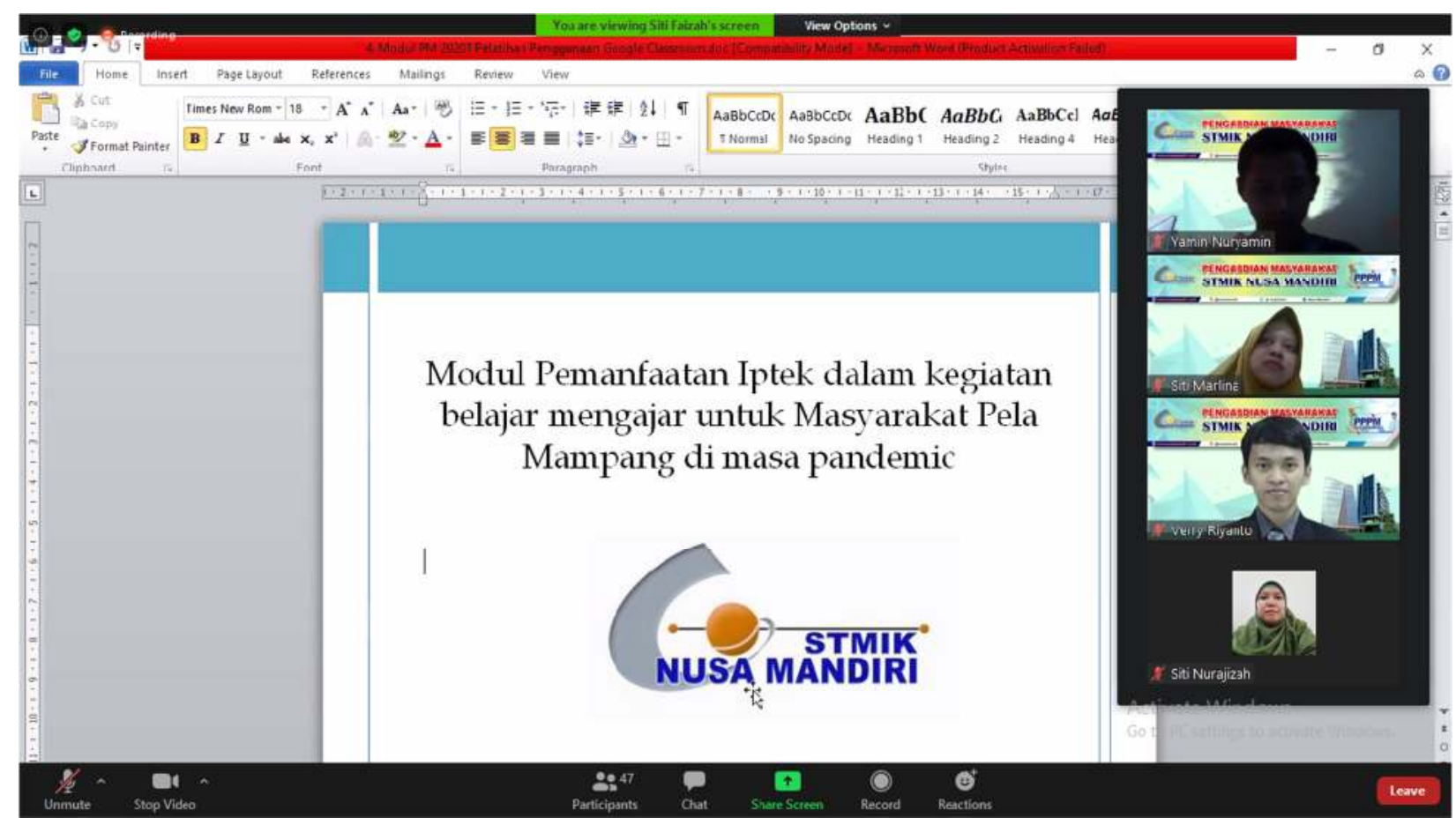

Sumber: Dokumentasi PM

Gambar 2. Dokumentasi penyampaian materi 


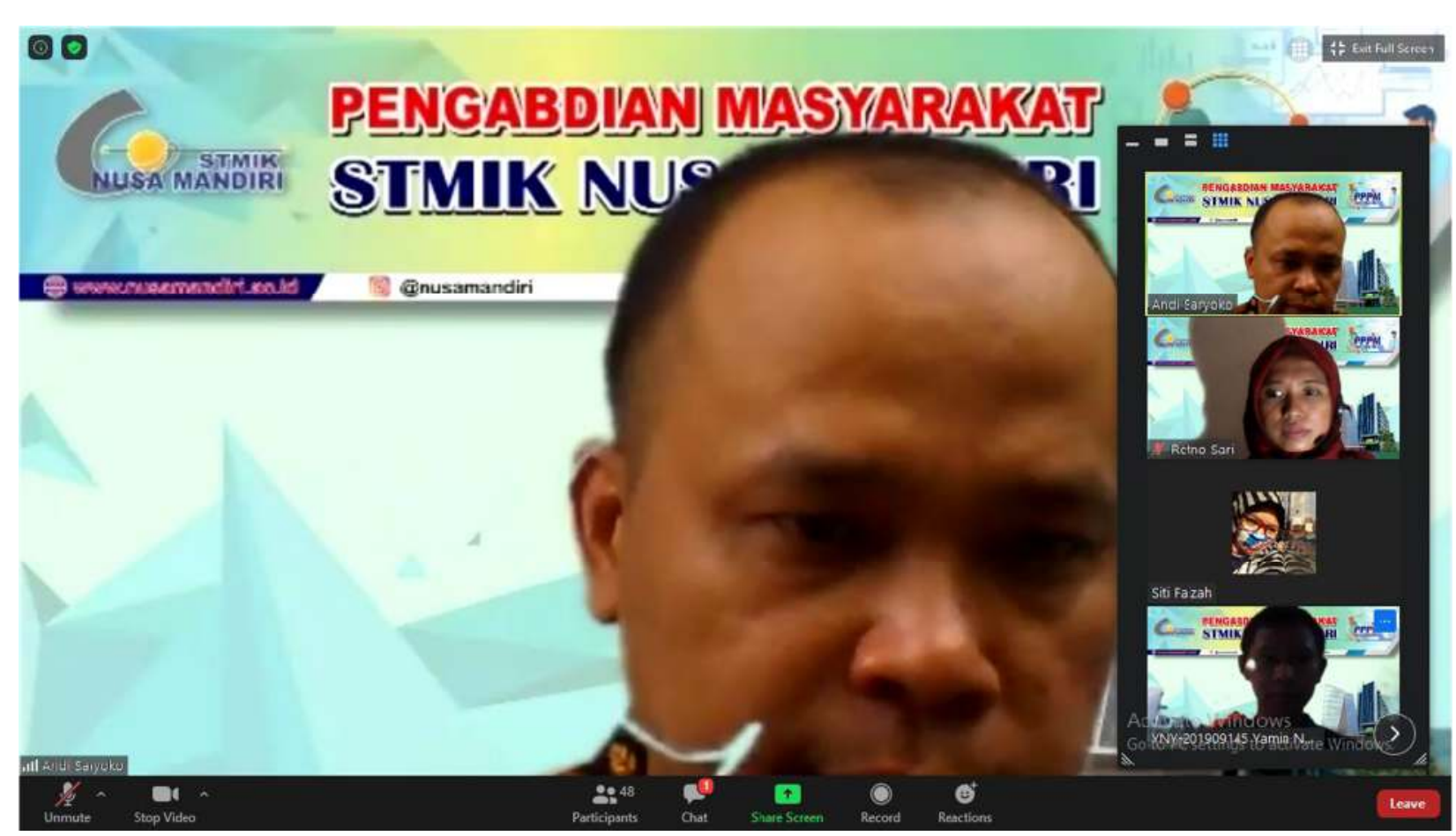

Sumber: Dokumentasi PM

\section{Gambar 3. Dokumentasi penyampaian materi}

Tabel 1. Rekap Kuesioner Peserta

\begin{tabular}{|c|c|c|c|c|c|}
\hline \multicolumn{2}{|c|}{ Nama Mitra } & \multicolumn{4}{|c|}{ : Warga Rt. 008/ 010 Pela Mampang } \\
\hline & \multicolumn{4}{|c|}{ : 27 September 2020} \\
\hline \multirow[b]{2}{*}{ No. } & \multicolumn{3}{|c|}{ Data Responden } & \multicolumn{2}{|c|}{ Jawaban } \\
\hline & $\begin{array}{c}\text { Nama } \\
\text { Responden }\end{array}$ & $\begin{array}{l}\text { L/ } \\
\mathbf{P}\end{array}$ & Umur & Pendapat & Saran \\
\hline 1 & $\begin{array}{l}\text { Azzahra } \\
\text { Melinda }\end{array}$ & $\mathbf{P}$ & $<30$ & Sangat bermanfaat dan seru & Ditingkatkan pelajaran nya \\
\hline 2 & $\begin{array}{l}\text { Ayu } \\
\text { Komalasari }\end{array}$ & $\mathbf{P}$ & $<30$ & bagus & bagus \\
\hline 3 & $\begin{array}{l}\text { Rahma Aprilia } \\
\text { Sahlan }\end{array}$ & $\mathbf{P}$ & $<30$ & Sangat puas & Sangat puas \\
\hline 4 & Cyntha & $\mathbf{P}$ & $<30$ & $\begin{array}{l}\text { menyampaikan informasi } \\
\text { dengan jelas dan lengkap }\end{array}$ & Zoom \\
\hline 5 & $\begin{array}{l}\text { Zahra } \\
\text { mawaddah } \\
\text { suciati }\end{array}$ & $\mathbf{P}$ & $<30$ & $\begin{array}{l}\text { Sangat bermanfaat bagi kami } \\
\text { untuk mengisi waktu luang. }\end{array}$ & $\begin{array}{l}\text { Untuk kedepan nya tetap } \\
\text { diadakan pengabdian } \\
\text { masyarakat. }\end{array}$ \\
\hline 6 & $\begin{array}{l}\text { Mutiara.Ram } \\
\text { adhani }\end{array}$ & $\mathbf{P}$ & $<30$ & Seru & Good job \\
\hline 7 & $\begin{array}{l}\text { Inayah zhafira } \\
\text { suciati }\end{array}$ & $\mathbf{P}$ & $<30$ & $\begin{array}{l}\text { Bagus karna dapat menambah } \\
\text { wawasan }\end{array}$ & $\begin{array}{l}\text { Agar pengabdian masyarakat } \\
\text { tetap dilakukan kedepannya }\end{array}$ \\
\hline 8 & $\begin{array}{l}\text { Faza ridha } \\
\text { kamalia }\end{array}$ & $\mathbf{P}$ & $<30$ & $\begin{array}{l}\text { Merupakan salah satu bagian } \\
\text { dari Tri Dharma Perguruan } \\
\text { tinggi }\end{array}$ & Saling membantu \\
\hline 9 & Sultan & $\mathbf{L}$ & $<30$ & $\begin{array}{l}\text { Pengetahuan yang di dapat } \\
\text { mudah di pahami }\end{array}$ & $\begin{array}{l}\text { Harus bisa lebih baik dari } \\
\text { sebelumnya }\end{array}$ \\
\hline
\end{tabular}




\begin{tabular}{|c|c|c|c|c|c|}
\hline \multicolumn{2}{|c|}{ Nama Mitra } & \multicolumn{4}{|c|}{ : Warga Rt. 008/ 010 Pela Mampang } \\
\hline \multicolumn{2}{|c|}{ Tanggal Kegiatan } & \multicolumn{4}{|c|}{ : 27 September 2020} \\
\hline \multirow[b]{2}{*}{ No. } & \multicolumn{3}{|c|}{ Data Responden } & \multicolumn{2}{|c|}{ Jawaban } \\
\hline & $\begin{array}{c}\text { Nama } \\
\text { Responden }\end{array}$ & $\begin{array}{l}\text { L/ } \\
P\end{array}$ & Umur & Pendapat & Saran \\
\hline 10 & Najwa Aulia & $\mathbf{P}$ & $<30$ & Sangat bermanfaat & $\begin{array}{l}\text { Bisa diadakan kembali } \\
\text { kegiatan ini }\end{array}$ \\
\hline 11 & $\begin{array}{l}\text { Syahrul } \\
\text { Romdoni }\end{array}$ & $\mathbf{L}$ & $<30$ & Bermanfaat & Durasi diperpanjang \\
\hline 12 & $\begin{array}{l}\text { Putri Dian } \\
\text { Tirany }\end{array}$ & $\mathbf{P}$ & $<30$ & Bermanfaat & $\begin{array}{l}\text { Semoga diadakan tahun depan } \\
\text { asekkk yuhuuu }\end{array}$ \\
\hline 13 & $\begin{array}{l}\text { Reyhan putra } \\
\text { widayat }\end{array}$ & $\mathbf{L}$ & $<30$ & biasa aja & biasa aja \\
\hline 14 & Erna Nuraini & $\mathbf{P}$ & $<30$ & Sangat bermanfaat & $\begin{array}{l}\text { Bisa diadakan kembali } \\
\text { kegiatan ini }\end{array}$ \\
\hline
\end{tabular}

Sumber: Kuesioner Peserta 